\title{
Transvaginal Ultrasound-indicated Cervical Cerclage Versus Vaginal Progesterone in Singleton Women with a Short Cervical Length: A Retrospective Study
}

Yijun Liu

West China Second University Hospital of Sichuan University

Tiantian Cao

West China Second University Hospital of Sichuan University

Shuai Zeng

West China Second University Hospital of Sichuan University

Ruixin Chen

West China Second University Hospital of Sichuan University

Xinghui Liu

West China Second University Hospital of Sichuan University

Lei He ( $\square$ helei0218@126.com )

West China Second University Hospital of Sichuan University

\section{Research Article}

Keywords: cervical cerclage, vaginal progesterone, singleton pregnancy, preterm birth, transvaginal ultrasound

Posted Date: February 23rd, 2021

DOl: https://doi.org/10.21203/rs.3.rs-225480/v1

License: (c) (i) This work is licensed under a Creative Commons Attribution 4.0 International License. Read Full License 


\section{Abstract}

Introduction: Cervical cerclage and vaginal progesterone are two primary methods for preventing preterm birth. However, their effectiveness in preventing singleton pregnancies with a short cervical length is unclear. We compared the effects of cervical cerclage and vaginal progesterone on the mother and neonate in asymptomatic singleton pregnancies in women with a cervical length between $10-30 \mathrm{~mm}$.

Material and Methods: Asymptomatic singleton pregnant women with a cervical length of $10-30 \mathrm{~mm}$, measured using transvaginal ultrasound at 12-26 weeks of gestation, who delivered at our hospital were enrolled. The primary outcome measure was preterm birth at $<37,34,32$, and 28 weeks of gestation. The secondary outcome measures were neonatal mortality, latency period from diagnosis to delivery, hemorrhage during delivery, birth weight, and cesarean delivery.

Results: In the unadjusted analysis, the number of preterm births was significantly higher in the cerclage group than in the vaginal progesterone group. After multivariate adjustment for confounding factors, this relationship narrowed. The latency period from diagnosis to delivery was significantly prolonged.

Conclusions: Cervical cerclage showed no benefit over vaginal progesterone in preventing preterm birth. However, it prolonged gestational age by 39 days compared to vaginal progesterone treatment.

\section{Introduction}

Preterm birth (PTB) is a major cause of neonatal mortality worldwide, seriously affecting maternal and neonatal health and causing heavy social and economic burden. Cervical incompetence, one of the major causes of miscarriage and PTB, refers to the inability of the cervix to maintain its normal morphology and function and maintain a pregnancy to term. This results in miscarriage or PTB [1].

Previous studies have shown that the sonographic measurement of cervical length (CL) can be a powerful indicator for predicting spontaneous preterm delivery of singletons [2-4]. Since asymptomatic shortening of $\mathrm{CL}$ can be identified by transvaginal ultrasound during a routine obstetric examination, most singleton pregnant women with high PTB risks are identifiable.

Cervical cerclage and vaginal progesterone are currently the two primary methods for preventing PTB. However, research into the effectiveness of these two therapies in preventing PTB in singleton pregnancies with short CL has yielded ambiguous results [5-8]. Clinically, there may be a bias toward the choice of cervical cerclage if the $\mathrm{CL}$ is short $(<10 \mathrm{~mm})$, and similarly, there may be a bias toward the choice of vaginal progesterone if the $\mathrm{CL}$ is long $(>30 \mathrm{~mm})$. However, there is no clear treatment option for singleton pregnant women with CL between $10 \mathrm{~mm}$ and $30 \mathrm{~mm}$. Furthermore, there is insufficient evidence to determine whether one treatment is superior to the other in preventing PTB and decreasing neonatal outcomes in singleton pregnancies, especially in singleton pregnant women with CL between 10 $\mathrm{mm}$ and $30 \mathrm{~mm}$. Within this range of $\mathrm{CL}$, it is extremely difficult for doctors and patients to choose a preferred treatment. We, therefore, conducted a retrospective study to directly compare the two 
controversial methods for singleton pregnant women whose cervix is between $10 \mathrm{~mm}$ and $30 \mathrm{~mm}$ in length.

\section{Methods}

This retrospective study was approved by the Institutional Ethics Committee of West China Second Hospital. Any kind of human experimental investigations was not involved in this research. Informed verbal consent was obtained telephonically from all participants included in the study to retrieve and use their medical records. All statistical methods were performed in accordance with relevant guidelines and regulations.

\section{Inclusion and exclusion criteria}

Asymptomatic singleton pregnant women with a CL between $10 \mathrm{~mm}$ to $30 \mathrm{~mm}$, measured using transvaginal ultrasound at 12-26 weeks of gestation, who delivered their babies at our hospital between January 2009 and August 2020, were included in our study. The exclusion criteria were as follows: maternal age $<18$ years, regular contractions, active uterine bleeding, clinical chorioamnionitis, fetal congenital malformations, and medically indicated PTB (such as severe preeclampsia, fetal distress, or placenta previa). A pregnant woman with elevated body temperature $\left(\geq 37.8^{\circ} \mathrm{C}\right)$ accompanied by two or more of the following symptoms and signs can be diagnosed with clinical chorioamnionitis: 1) maternal heart rate symptoms and signs that can be treated by ritodrine hydrochloride, 2) fetal tachycardia (chloride symptoms excluding the influence of ritodrine hydrochloride), 3) elevated maternal white blood cell count (excluding the influence of dexamethasone), 4) elevated C-reactive protein or procalcitonin, 5) foul-smelling amniotic fluid (pay attention to the color of the amniotic fluid and promptly look for amniotic fluid fecal stain), and 6) uterine tenderness or irritability.

\section{Treatment procedures}

All cerclage surgeries were performed by experienced professors using the standard McDonald cervical cerclage method [9]. Preoperative procedures included an evaluation of cervical conditions such as contractions, a vaginal examination, and identification of infection indicators to determine the technical feasibility of cerclage placement. All patients underwent combined spinal-epidural anesthesia; the cervix was exposed using a vaginal retractor, and the front lip of the cervix was held open with oval forceps. The procedure was conducted by stitching the cervix, at the level of the internal cervix close to the vaginal fornix, from the 11 o'clock position to the 9 to 10 o'clock position. The suture was then looped several times, and the last stitch was placed at the 1 o'clock position and tightened around the cervix. The duration of antibiotic use depended on postoperative body temperature, blood routine, and C-reactive protein value. Uterine contraction inhibitors were used during the perioperative period. The vaginal progesterone group was treated with a single dose of $90 \mathrm{mg}$ progesterone gel. These patients were treated in outpatient clinics, and if they were hospitalized due to symptoms of miscarriage or premature birth, uterine contraction inhibitors were also used. 


\section{Measurement of cervical length}

All sonographers were licensed practitioners who had received training in vaginal CL measurement.

\section{Data collection}

Data collected included maternal age, body mass index, CL measurement before treatment, history of preterm delivery, history of cervical injury, indicators of a pre-treatment blood infection (white blood cell count and percentage of neutrophils), pregnancy complications, gestational weeks at delivery, mode of delivery, hemorrhage during delivery, neonatal survival outcomes, and birth weight. Based on these data, we formulated two models for our study.

\section{Primary and secondary outcomes}

The primary outcomes were PTB at $<37$ weeks, $<34$ weeks, $<32$ weeks, and $<28$ weeks of gestation. Neonatal mortality, latency period from diagnosis of a CL between $10 \mathrm{~mm}$ and $30 \mathrm{~mm}$ to delivery, hemorrhage during delivery, birth weight, and cesarean delivery were studied as secondary outcomes.

\section{Statistical analysis}

We used SAS 9.4 (TS1M6, Cary, NC, USA) for data analysis. For data that followed, or approximately followed, normal distribution, we used a form of the mean and standard deviation to describe the data distribution and an independent sample t-test to analyze it. For data that did not follow a normal distribution, we used the median (upper quartile, lower quartile) for description and the nonparametric test (U test) for differential analysis. Count data were described using frequency (percentage, \%), and the chisquare test was used for analysis (including the continuity correction method). In terms of gestation weeks at delivery and neonatal outcomes, a Cox semiparametric regression model was established. For the latency period from diagnosis to delivery and hemorrhage during delivery (a non-normal, natural logarithmic transformation was used), a generalized linear regression model was established. For birth weight (ordinal variable), an ordinal logistic regression model was used; to decide whether to perform cesarean delivery, a binary logistic regression model was used. Only treatment method was included in Model 1 for statistics. For Model 2, we adjusted the balanced variables in the baseline data. Additionally, we used hazard ratio (HR), odds ratio (OR), and partial regression coefficient $\beta$ as risk assessment indicators in both Models 1 and 2. $P<0.05$ was considered statistically significant. All the P-values reported were two-sided. We analyzed the data using traditional confounder adjustment.

\section{Results}

The demographic characteristics of the two groups were not significantly different. A total of 359 asymptomatic singleton pregnancies where the $C L$ was between $10 \mathrm{~mm}$ and $30 \mathrm{~mm}$ were initially included in this study. Of these, 92 cases were excluded from the analysis: 83 because they were medically indicated for preterm delivery and nine because they underwent pessary placement. Finally, a 
total of 267 singleton pregnant women, of which 116 had cervical cerclage and 151 had vaginal progesterone, were retrospectively analyzed (Fig. 1).

The baseline characteristics of mean gestational age ( 30.0 vs. 31.0 weeks), body mass index (23.67 \pm 3.53 vs. $23.82 \pm 3.34 \mathrm{~kg} / \mathrm{m}^{2}$ ), CL measurement before treatment ( $18 \mathrm{~mm}$ vs. $20 \mathrm{~mm}$ ), white blood cell count (9.1 vs. 9.2), percentage of neutrophils (75.85 vs. 76.00$)$, and other related medical histories (previous preterm delivery, cervical injury, and pregnancy complications) were similar between women in the cerclage group and those in the control group. The baseline characteristics of the two groups were therefore not significantly different (Table 1). The HR and OR for each of the primary and secondary outcomes are shown in Table 2. 
Table 1

Baseline characteristics of the maternal participants

\begin{tabular}{|c|c|c|c|c|}
\hline Characteristic & $\begin{array}{l}\text { Cervical cerclage } \\
\text { group }(n=116)\end{array}$ & $\begin{array}{l}\text { Vaginal progesterone } \\
\text { group }(n=151)\end{array}$ & $t / Z / \chi 2$ & $\mathbf{P}$ \\
\hline Age, median (IQR) & $\begin{array}{l}30.00(28.00 \\
34.00)\end{array}$ & $31.00(28.00,34.00)$ & -0.569 & 0.570 \\
\hline $\mathrm{BMI}$, mean $\pm \mathrm{SD}$ & $23.67 \pm 3.53$ & $23.82 \pm 3.34$ & 0.347 & 0.729 \\
\hline $\begin{array}{l}\mathrm{CL} \text { measurement before } \\
\text { treatment }(\mathrm{cm}) \text {, median (IQR) }\end{array}$ & $1.80(1.50,2.40)$ & $2.00(1.40,2.20)$ & -0.453 & 0.650 \\
\hline $\begin{array}{l}\text { White blood cell count, median } \\
\text { (IQR) }\end{array}$ & $9.10(7.90,11.38)$ & $9.20(7.60,11.13)$ & -0.349 & 0.727 \\
\hline $\begin{array}{l}\text { Percentage of neutrophils, } \\
\text { median (IQR) }\end{array}$ & $\begin{array}{l}75.85(72.93 \\
80.30)\end{array}$ & $76.00(72.98,79.18)$ & -0.124 & 0.901 \\
\hline Pregnancy complications (\%) & & & 2.637 & 0.104 \\
\hline No & $93(80.2)$ & $108(71.5)$ & & \\
\hline Yes & $23(19.8)$ & $43(28.5)$ & & \\
\hline $\begin{array}{l}\text { Previous history of cervical } \\
\text { injury (\%) }\end{array}$ & & & 0.007 & 0.932 \\
\hline No & $111(95.7)$ & $143(94.7)$ & & \\
\hline Yes & $5(4.3)$ & $8(5.3)$ & & \\
\hline Previous history of PTB (\%) & & & 0.038 & 0.450 \\
\hline No & $109(94.0)$ & $141(93.4)$ & & \\
\hline Yes & $7(6.0)$ & $10(6.6)$ & & \\
\hline $\begin{array}{l}\text { Membranes ruptured before } \\
\text { treatment (\%) }\end{array}$ & & & 0.118 & 0.732 \\
\hline No & $103(88.8)$ & $132(87.4)$ & & \\
\hline Yes & $13(11.2)$ & $19(12.6)$ & & \\
\hline
\end{tabular}


Table 2

Primary and secondary outcomes in the cerclage and vaginal progesterone groups

\begin{tabular}{|c|c|c|c|c|}
\hline & Model $1^{*}$ crude & $\begin{array}{l}\text { P } \\
\text { crude }\end{array}$ & Model $2^{\# \text {-adjusted }}$ & $\begin{array}{l}\text { P- } \\
\text { adjusted }\end{array}$ \\
\hline \multicolumn{5}{|l|}{ Primary outcome } \\
\hline Delivery $<28^{a}$ & $\begin{array}{l}4.147(1.863 \\
9.234)\end{array}$ & 0.001 & $\begin{array}{l}4.195(1.868 \\
9.421)\end{array}$ & 0.001 \\
\hline Delivery $<32^{\mathrm{a}}$ & $\begin{array}{l}2.738(1.626 \\
4.609)\end{array}$ & 0.001 & $\begin{array}{l}2.957(1.743 \\
5.018)\end{array}$ & 0.001 \\
\hline Delivery $<34^{a}$ & $2.653(1.663,4.231)$ & 0.001 & $\begin{array}{l}2.897(1.803 \\
4.655)\end{array}$ & 0.001 \\
\hline Delivery $<37^{a}$ & $\begin{array}{l}1.529(1.076 \\
2.172)\end{array}$ & 0.018 & $\begin{array}{l}1.739(1.213 \\
2.494)\end{array}$ & 0.003 \\
\hline \multicolumn{5}{|l|}{ Secondary outcomes } \\
\hline Neonatal mortality ${ }^{a}$ & $\begin{array}{l}3.519(1.364 \\
9.079)\end{array}$ & 0.009 & $\begin{array}{l}3.513(1.350 \\
9.145)\end{array}$ & 0.010 \\
\hline $\begin{array}{l}\text { Latency period from diagnosis to } \\
\text { delivery }{ }^{b}\end{array}$ & $\begin{array}{l}39.840 \\
(29.827,49.853)\end{array}$ & 0.001 & $\begin{array}{l}38.486 \\
(29.295,47.678)\end{array}$ & 0.001 \\
\hline $\begin{array}{l}\text { Hemorrhage during delivery (In- } \\
\text { trans) }{ }^{b}\end{array}$ & $\begin{array}{l}-0.084(-0.233 \\
0.066)\end{array}$ & 0.271 & $\begin{array}{l}-0.064(-0.207 \\
0.080)\end{array}$ & 0.384 \\
\hline Birth weight ${ }^{\mathrm{C}}$ & $\begin{array}{l}0.370(0.224 \\
0.610)\end{array}$ & 0.001 & $\begin{array}{l}0.332(0.196 \\
0.561)\end{array}$ & 0.001 \\
\hline Cesarean delivery $^{d}$ & $\begin{array}{l}0.844(0.510 \\
1.397)\end{array}$ & 0.509 & $\begin{array}{l}0.836(0.499 \\
1.400)\end{array}$ & 0.496 \\
\hline
\end{tabular}

a: Cox semiparametric regression model; b: generalized linear regression model; c: ordinal logistic regression model; d: binary logistic regression model;

\section{* Model 1; \# Model 2}

Model 1, the univariate analysis that only incorporated the treatment method, showed that compared with the vaginal progesterone group, the cerclage group had a higher risk of PTB at < 37 weeks (HR, 1.529; 95\% confidence interval [Cl] 1.076-2.172), < 34 weeks (HR, 2.653; 95\% Cl 1.663-4.231), < 32 weeks (HR, $2.738 ; 95 \% \mathrm{Cl} 1.626-4.609)$, and < 28 weeks (HR, 4.147; 95\% Cl 1.863-9.234) of gestation.

Model 2 was the multivariable Cox risk factor regression model adjusted for potential confounders (age, body mass index, CL measurement before treatment, white blood cell count, percentage of neutrophils, pregnancy complications, history of cervical injury, history of PTB, and ruptured membranes before treatment). This analysis showed a more prominent correlation between cervical cerclage and PTB. 
Compared with the vaginal progesterone group, the cerclage group had an increased risk of PTB at $<37$ weeks (HR, 1.739; 95\% Cl 1.213-2.494), < 34 weeks (HR, 2.897; 95\% Cl 1.803-4.655), < 32 weeks (HR, $2.957 ; 95 \% \mathrm{Cl} 1.743-5.018)$, and $<28$ weeks (HR, 4.195; 95\% Cl 1.868-9.421) of gestation, latency period from diagnosing to delivery $(\beta 38.486 ; 95 \% \mathrm{Cl} 29.295-47.678)$, and neonatal mortality $(\mathrm{HR}, 3.513 ; 95 \% \mathrm{Cl}$ 1.350-9.145). Furthermore, the cerclage group was associated with a higher risk of low birth weight (OR $0.370,95 \% \mathrm{Cl} 0.244-0.610)$. Notably, in the ordinal logistic regression for birth weight, OR represents the risk or quantitative relationship of the outcome with a larger assignment (the birth weight is assigned as follows: less than $1,500 \mathrm{~g}=1 ; 1,500-2,500 \mathrm{~g}=2$; greater than $2,500 \mathrm{~g}=3$ ). There was no statistical significance in the variables hemorrhage during delivery and cesarean delivery.

The Kaplan-Meier plots displayed a statistically significant difference in PTB at $<37,<34,<32$, and $<28$ weeks of gestation between the cerclage and vaginal progesterone curves $(P<0.05)$ overall $(F i g s .2,3,4$, and 5).

\section{Discussion}

In our initial, unadjusted model, cervical cerclage was found to be associated with an increased risk of PTB in this cohort of singleton pregnancies with a CL between $10 \mathrm{~mm}$ to $30 \mathrm{~mm}$, compared to vaginal progesterone administration. This relationship was further narrowed after adjustment for confounders by risk factor regression analysis. However, cervical cerclage significantly prolonged the latency period from diagnosing to delivery. A possible reason for this result is that when the $\mathrm{CL}$ is shortened, many singleton pregnant women are more inclined to receive conservative treatment than preventive cervical cerclage. However, when the length of the cervix is progressively shortened, rescue cervical cerclage must be performed to extend the gestational age. Most studies have reported that cervical cerclage is effective in preventing spontaneous PTB compared to other treatments, especially for women with a short cervix [2, $10,11]$. Wood pointed out that compared to vaginal progesterone treatment in singleton pregnant women with $\mathrm{CL} \leq 25 \mathrm{~mm}$ and no history of PTB or cerclage, cervical cerclage did not reduce the risk of PTB [12], which is consistent with our study. Similarly, a meta-analysis of five high-quality randomized controlled trials involving 974 singleton pregnancies with a short cervix (498 for vaginal progesterone group and 476 for the placebo group) indicated that the risk of spontaneous PTB $<33$ weeks of gestation in the vaginal progesterone group was significantly reduced by $38 \%$ [13]. However, the results from a multicenter randomized double-blind trial conducted by Norman et al. indicated that vaginal progesterone was not associated with reduced risk of PTB or composite neonatal adverse outcomes and had no longterm benefit or harm on outcomes in children at 2 years of age [14]. Studies mention that for singleton pregnant women with a shortened cervix, when the length of the cervix is progressively shortened, vaginal progesterone can be administered, and adjuvant vaginal progesterone leads to prolonged gestational weeks and increased birth weight [15]. Therefore, we recommend that when treating a singleton woman, the length of the cervix should be monitored regularly. If the $\mathrm{CL}$ is found to be progressively shortened, cervical cerclage can be performed with or without vaginal progesterone. It may, therefore, be useful to conduct a large-scale prospective study in the future with an experimental group treated using cervical cerclage + progesterone and a control group which only receives cervical cerclage. For ethical reasons, it 
is difficult for us to use blank controls. In addition to collecting maternal outcomes, it is also necessary to follow-up on neonatal outcomes. It should be noted that braided sutures were used in cervical cerclage surgery in our hospital. Kindinger et al. pointed out that braided cerclage is associated with increased intrauterine death $(15 \%$ versus $5 \% ; \mathrm{P}<0.001)$ and PTB $(28 \%$ versus $17 \% ; \mathrm{P}<0.001)$ compared to monofilament suture [16]. Additionally, a prospective observational study indicated that a reduction in the relative abundance of Lactobacillus spp. is associated with PTB [17]. The vaginal micro-ecological environment may be related to the onset of labor. In this study, there is a lack of data on leukorrhea routine before treatment; thus, it cannot be used as an independent variable for analysis. Nonetheless, the ultimate goal of any treatment method is to prolong the gestational age, win opportunities for fetal growth in the uterus, and promote the maturity of the fetal lungs, thereby reducing the occurrence of adverse neonatal outcomes.

The primary strength of this study is the inclusion of an adequate sample size to assess the effects of cervical cerclage and vaginal progesterone in pregnant women with a CL between $10 \mathrm{~mm}$ and $30 \mathrm{~mm}$ and statistical correction for confounding factors.

The findings of our study also showed several limitations. First, there are currently no uniform criteria for determining whether study subjects are eligible for cervical cerclage or vaginal progesterone treatment, which may present some cases of noncompliance. Second, the exclusion of patients with medically indicated preterm delivery may have led to a bias. Third, insufficient data on major neonatal morbidities, including Neonatal Intensive Care Unit admission, Apgar scores, respiratory distress syndrome, intraventricular hemorrhage, and necrotizing enterocolitis, were collected to compare neonatal outcomes between the two groups. Fourth, we included pregnant women with a CL between $10 \mathrm{~mm}$ and $30 \mathrm{~mm}$, excluding singleton pregnancies with all CL ranges, limiting our ability to compare our study population to the entire cohort of singleton PTB.

The primary aim of all treatments is to prolong the gestational age, allow fetal growth in the uterus, and promote the maturity of the fetal lungs, thereby reducing the occurrence of adverse neonatal outcomes. In our study, we found that cervical cerclage did not have significant advantages over vaginal progesterone therapy in preventing preterm birth. However, it was able to prolong gestational age by 39 days compared to vaginal progesterone treatment.

\section{Declarations}

\section{Data availability}

The original datasets generated during and analysed during the current study are available from the corresponding author on reasonable request.

\section{Conflicts of interest}


The authors declare no competing interests.

\section{Financial information}

This work was supported by the National Key Research and Development Program of China (2018YFC1004603).

\section{Acknowledgments}

We would like to thank Editage (www.editage.cn) for English language editing. We express our gratitude to all the individuals who participated in this study.

\section{Authors' contributions}

$\mathrm{YL}, \mathrm{TC}$, and SZ contributed to data collection and the conceptualization of the study. $\mathrm{YL}$ and RC contributed to the study design. $\mathrm{YL}, \mathrm{XL}$, and LH contributed to data analysis. All the authors contributed to data interpretation, manuscript preparation, editing, and review. All authors have read and approved the final manuscript.

\section{References}

1. Gudicha, D. W. et al. Personalized assessment of cervical length improves prediction of spontaneous PTB: a standard and a percentile calculator. J. Obstet. Gynecol. 10.1016/j.ajog.2020.09.002 (2020).

2. Althuisius, S. M. et al. Cervical incompetence prevention randomized cerclage trial (CIPRACT): study design and preliminary results. J. Obstet. Gynecol. 183, 823-829 (2000)

3. To, M. S. et al. Cervical length and funneling at 23 weeks of gestation in the prediction of spontaneous early preterm delivery. Ultrasound Obstet. Gynecol. 18, 200-203 (2001).

4. Diawtipsukon S. et al. The comparative study of cervical shear wave elastography between twin and singleton pregnancy. J. Womens Health 12, 649-656 (2020)

5. Pustotina, $\mathrm{O}$. Effectiveness of dydrogesterone, $17-\mathrm{OH}$ progesterone and micronized progesterone in prevention of PTB in women with a short cervix. Matern. Fetal Neonatal. Med. 31, 1830-1838 (2018)

6. Otsuki, K. et al. Randomized trial of ultrasound-indicated cerclage in singleton women without lower genital tract inflammation. Obstet. Gynaecol. Res. 42, 148-157 (2016)

7. Conde-Agudelo, D. A. et al. Vaginal progesterone is as effective as cervical cerclage to prevent PTB in women with a singleton gestation, previous spontaneous PTB, and a short cervix: updated indirect comparison meta-analysis. J. Obstet. Gynecol. 219, 10-25 (2018)

8. Jarde, A. et al. Vaginal progesterone, oral progesterone, 17-OHPC, cerclage, and pessary for preventing preterm birth in at-risk singleton pregnancies: An updated systematic review and network 
meta-analysis. Obstet Gynecol Surv. 74, 516-518 (2019)

9. Brown, R., Gagnon, R. \& Delisle, M. F. No. 373-Cervical Insufficiency and Cervical Cerclage. Obstet. Gynaecol. Can. 41, 233-247 (2019)

10. Owen, J. et al. Multicenter randomized trial of cerclage for preterm birth prevention in high-risk women with shortened mid-trimester cervical length. J. Obstet. Gynecol. 201, 375.e1-8 (2009)

11. Berghella, V. et al. Cerclage for sonographic short cervix in singleton gestations without prior spontaneous preterm birth: systematic review and meta-analysis of randomized controlled trials using individual patient-level data. Obstet. Gynecol. 50, 569-577 (2017)

12. Wood, A. M., Dotters-Katz, S. K. \& Hughes, B. L. Cervical cerclage versus vaginal progesterone for management of short cervix in low-risk women. J. Perinatol. 36, 111-117 (2019)

13. Romero, R. et al. Vaginal progesterone for preventing preterm birth and adverse perinatal outcomes in singleton gestations with a short cervix: a meta-analysis of individual patient data. J. Obstet. Gynecol. 218, 161-180 (2018)

14. Norman, J. E. et al. Vaginal progesterone prophylaxis for preterm birth (the OPPTIMUM study): a multicentre, randomised, double-blind trial. 387, 2106-2116 (2016)

15. Alina, R. et al. Rescue adjuvant vaginal progesterone may improve outcomes in cervical cerclage failure. Geburtshilfe Frauenheilkd. 78, 785-790 (2018)

16. Kindinger, L.M. et al. Relationship between vaginal microbial dysbiosis, inflammation, and pregnancy outcomes in cervical cerclage. Transl. Med. 8, 350ra102 (2016)

17. Brown, R. G., et al. Prospective observational study of vaginal microbiota pre- and post-rescue cervical cerclage. 126, 916-925 (2019)

\section{Figures}




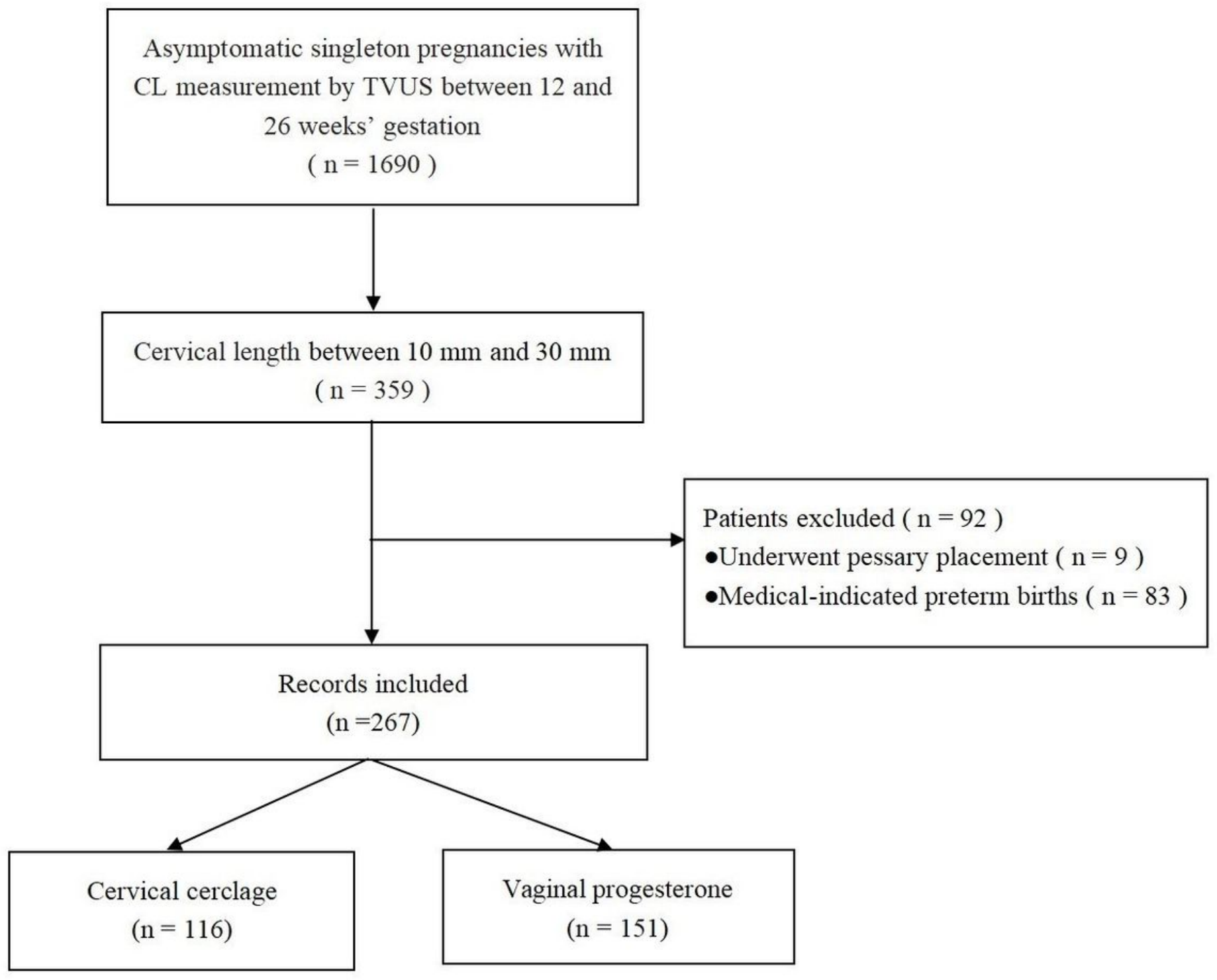

Figure 1

Screening process used to select participants. CL, cervical length; TVUS, transvaginal ultrasound 


\section{Delivery $<37$}

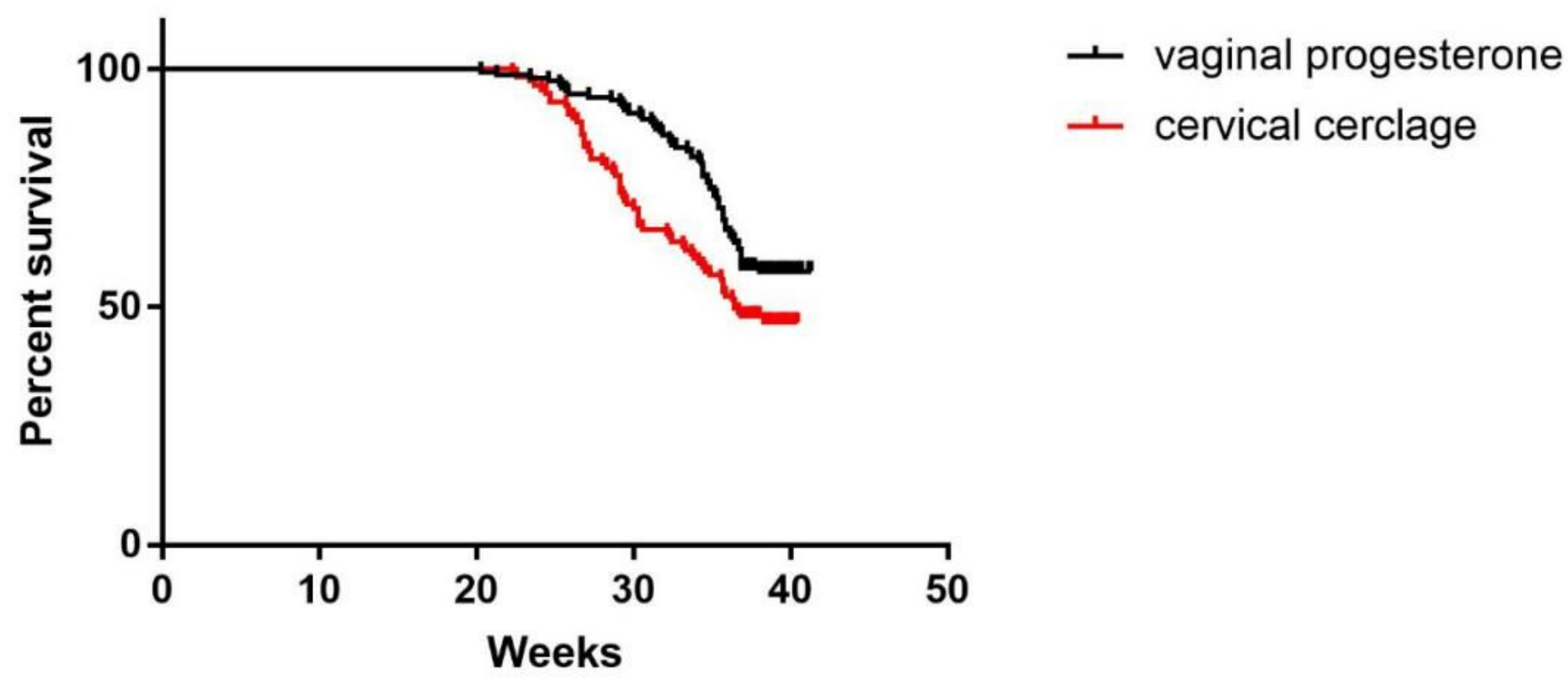

Figure 2

Kaplan-Meier plot of the probability of continued pregnancy without delivery where the primary outcome is delivery at less than 37 weeks.

Delivery $<34$

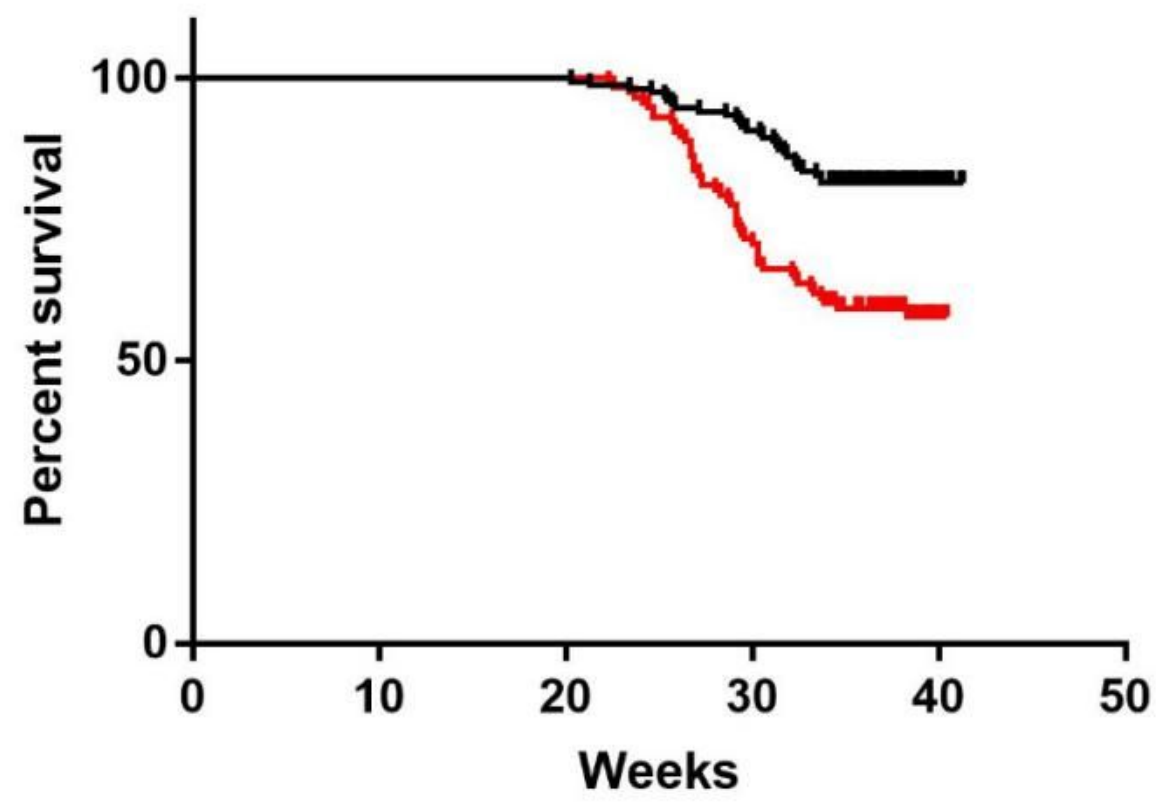

ـ vaginal progesterone

+ cervical cerclage 
Figure 3

Kaplan-Meier plot of the probability of continued pregnancy without delivery where the primary outcome is delivery at less than 34 weeks.

\section{Delivery $<32$}

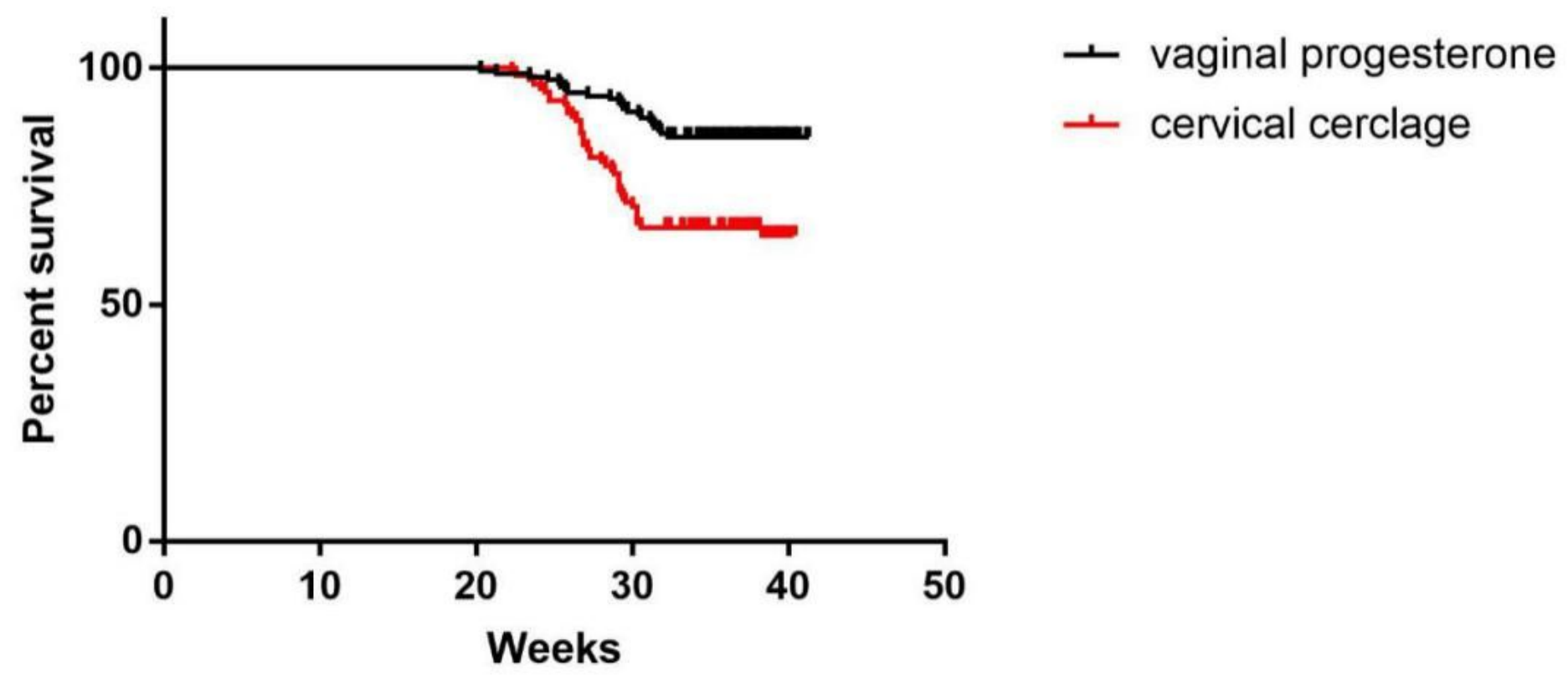

Figure 4

Kaplan-Meier plot of the probability of continued pregnancy without delivery where the primary outcome is delivery at less than 32 weeks. 


\section{Delivery $<28$}

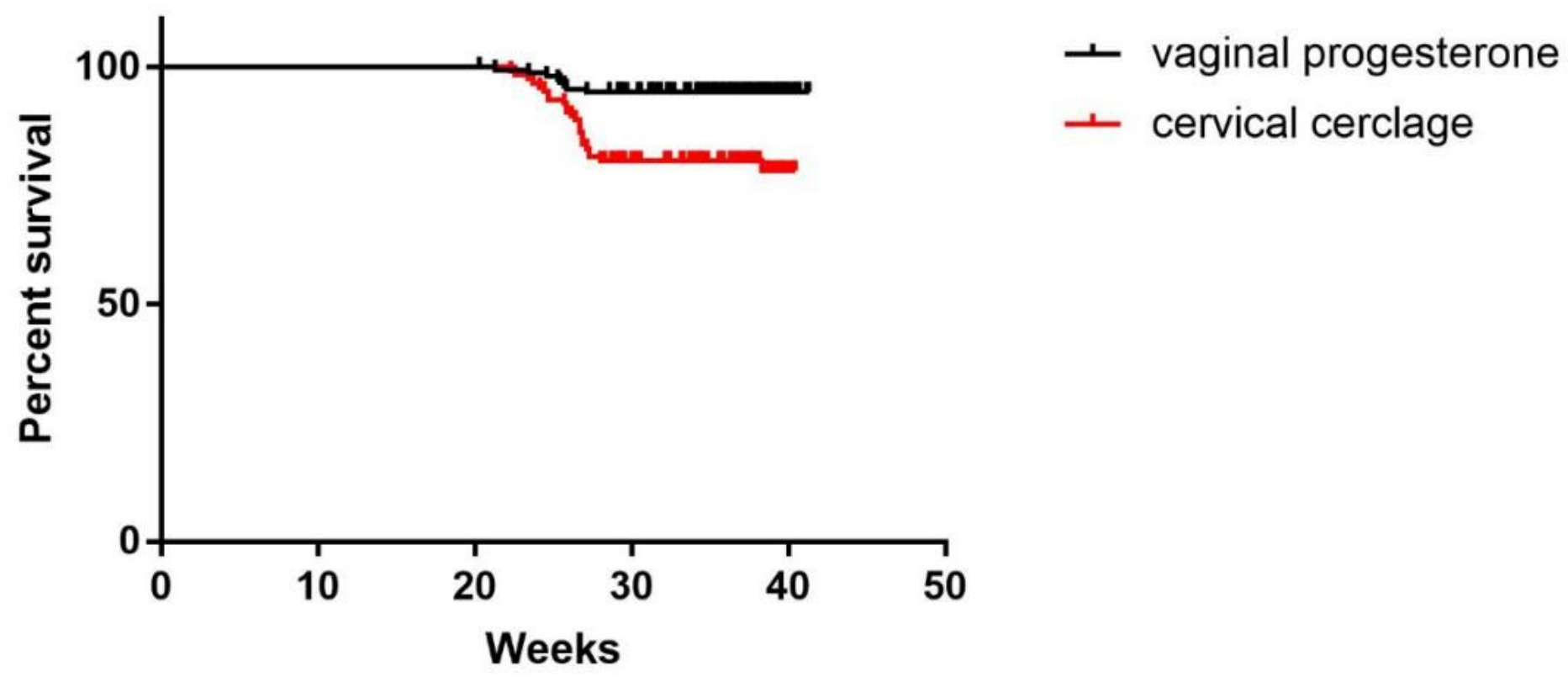

Figure 5

Kaplan-Meier plot of the probability of continued pregnancy without delivery where the primary outcome is delivery at less than 28 weeks.

\section{Supplementary Files}

This is a list of supplementary files associated with this preprint. Click to download.

- Tables.doc 